\title{
Gestão dos filtros de óleo lubrificantes automotivos pós-consumo: estudo de caso nos pontos de trocas de óleo na cidade de Alagoinhas -BA
}

Almir de Jesus Sampaio almirsampaio26@gmail.com Faculdade Santíssimo Sacramento (F.SS.S), Alagoinhas, Bahia, Brasil

\section{Helen Cristine Ribeiro Barbosa} helcrb@gmail.com

Faculdade Santíssimo Sacramento (F.SS.S), Alagoinhas, Bahia, Brasil

\section{Luis Gabriel Maggioni} Gabrielmagioni.10@gmail.com Faculdade Santíssimo Sacramento (F.SS.S), Alagoinhas, Bahia, Brasil

Jeane Denise de Souza Menezes Menezes220@gmail.com Faculdade Santíssimo Sacramento (F.SS.S), Alagoinhas, Bahia, Brasil

\begin{abstract}
RESUMO
A expansão da aquisição de veículos automotores nos últimos anos, trouxe como consequência o aumento dos resíduos gerados pelas manutenções dos veículos, sendo que resíduos provenientes dessa atividade, especialmente os filtros de óleos lubrificantes utilizados, possuem um alto poder de degradação ao meio ambiente e prejuízo à saúde pública, caso sejam descartados incorretamente. O estudo de caso realizado na cidade de Alagoinhas BA visa mostrar a realidade do descarte inadequado dos filtros e o esforço dos proprietários para mitigar os danos causados por esse item após seu consumo. Foram realizadas entrevistas orientadas em pontos de trocas de óleo/filtros, com intuito de diagnosticar a gestão do resíduo em questão. A área de estudo foi delimitada em uma área com raio de $7 \mathrm{~km}$ do centro da cidade, através do aplicativo Waze. Apesar de boa parte desses resíduos serem destinados para empresas e cooperativas, os dados mostram que $25 \%$ dos locais averiguados ainda destinam os filtros utilizados à coleta pública municipal. Ainda percebe-se que cerca de $58 \%$ desses locais não possuem programa de logística reversa. Com isso, é notória a necessidade da implantação desse tipo de medida como solução a essa problemática, bem como a conscientização da responsabilidade compartilhada entre poder público, empresas e seus consumidores.
\end{abstract}

PALAVRAS-CHAVE: Filtros de óleo. Manutenção automotiva. Resíduos oleosos. 


\section{INTRODUÇÃO}

A população do Brasil tem crescido de forma considerável nos últimos anos. Desde 2010 até então, a população brasileira teve um aumento de aproximadamente 16 milhões de habitantes até o ano de 2018 (IBGE, 2019), fenômeno que foi acompanhado por uma expansão no mercado automobilístico. Estima-se que, nesse período, houve um aumento de $54 \%$ da frota de veículos leves, segundo dados do Departamento Nacional de Trânsito (DENATRAN, 2018) cuja causa pode ser explicada, em parte, pelo aumento de incentivos, dentre os quais a redução do Imposto sobre Produtos Industrializados (IPI) na aquisição destes bens.

Com isso, houve uma progressiva demanda por procedimentos de manutenção automotiva, cuja consequência prática foi o aumento na geração de resíduos sólidos como subprodutos. A NBR 10004 os define como "resíduos nos estados sólido e semissólido, que resultam de atividades de origem industrial, doméstica, hospitalar, comercial, agrícola, de serviços e de varrição" (ABNT, 2004) e na lógica dos serviços automobilísticos incluem latas de óleo automotivo, estopas, peças inservíveis e, principalmente, filtros de óleo usados. Esses últimos têm ainda como agravante sua inevitável contaminação com óleo lubrificante automotivo, que é classificado como resíduo perigoso, considerando "suas características de inflamabilidade, corrosividade, reatividade, toxicidade, [...] carcinogenicidade, [...]" (ABNT, 2004). Há de se considerar ainda que o grande volume gerado desses resíduos acaba por acentuar as dificuldades já enfrentadas pela gestão de resíduos sólidos na maioria das cidades do Brasil.

É de conhecimento geral que a gestão de resíduos é uma das grandes preocupações, não apenas em cidades de menor porte como Alagoinhas-BA, mas de todo o cenário brasileiro atual. A amplitude desse problema assume maiores proporções no âmbito de manutenções automotivas, quando se trata dos filtros de óleo utilizados, pois via de regra são descartados de maneira arbitrária após sua substituição, normalmente como resíduos comuns. Algumas das causas que contribuem para a má gestão desse resíduo especificamente relacionam-se à carência de programas - embora existentes - e incentivos governamentais para sua reciclagem, já que a periculosidade a ele relacionada ainda dificulta a gestão de grandes volumes.

Ainda assim, é possível identificar a preocupação de algumas associações em participar de programas de reciclagem e destinação desse resíduo, como por exemplo, a ABRAFILTROS - Associação Brasileira das Empresas de Filtros e seus Sistemas, que realiza, através do Programa Descarte Consciente, a logística reversa de filtros de óleo utilizados. Embora seja realizada apenas em alguns estados do Sul, sudeste e Centro-oeste brasileiro, tal iniciativa é uma porta aberta para que as demais áreas do país tomem conhecimento da magnitude e importância dessa causa.

Sendo assim, o artigo em questão tem como foco mostrar como ocorre a gestão dos filtros utilizados em uma cidade do interior baiano, Alagoinhas, localizada a $117 \mathrm{~km}$ da capital, que viu sua frota de veículos automotores expandir-se de forma impressionante nos últimos anos e, como consequência, 
trouxe à cidade uma enorme quantidade de resíduos gerados diariamente, prejudicando a saúde pública e o meio ambiente.

\section{REFERENCIAL TEORICO}

\section{RESÍDUOS SÓLIDOS}

A velocidade com a qual os bens de consumo são lançados no mercado traz consigo um grande problema, que é a geração de resíduos sólidos e semissólidos, considerando que, em grande parte dos casos, não possuem uma destinação ambientalmente adequada. Segundo Muniz e Braga (2015), as degradações ambientais agravaram-se com as formações dos centros urbanos e a Revolução Industrial do século XVIII, que mecanizou os processos produtivos e intensificou a produção de bens destinados ao mercado. Atualmente, os impactos causados pela geração e descarte inadequados desses resíduos tornouse algo preocupante para as entidades responsáveis por esse passivo (BARROS, et al., 2018).

Os filtros de óleo lubrificantes automotivos, após seu uso, são classificados como resíduos sólidos em função de suas características físicas. A Política Nacional de Resíduos Sólidos - PNRS define esses resíduos como:

\footnotetext{
Material, substância, objeto ou bem descartado resultante de atividades humanas em sociedade, a cuja destinação final se procede, se propõe proceder ou se está obrigado a proceder, nos estados sólido ou semissólido, bem como gases contidos em recipientes e líquidos cujas particularidades tornem inviável o seu lançamento na rede pública de esgotos ou em corpos d'água, ou exijam para isso soluções técnica ou economicamente inviáveis em face da melhor tecnologia disponível (BRASIL, 2010).
}

Os filtros de óleo automotivo, enquanto resíduo, necessitam de soluções técnicas, já que os mesmos são compostos materiais de naturezas distintas. Sua formação é dada por [...] tampa, caneca, válvula e juntas de vedação [...] (PASQUALETTO; MACHADO; MORAIS, 2017). Dessa forma, se faz necessário uma segregação de todo o material, para que cada um receba sua destinação correta, inclusive o Óleo Lubrificante Usado e Contaminado - OLUC, visto que esse, por sua vez, se mostra um grande obstáculo para uma reciclagem eficiente desse componente.

O OLUC encontrado no interior dos filtros possui uma destinação especifica conforme Resolução 362/05 do Conselho Nacional do Ambiente - CONAMA. Todo óleo lubrificante contaminado e usado deve ser destinado através de coletores para os rerrefinadores, que são pessoas jurídicas responsáveis e autorizadas pelo refino desse material (CONAMA, 2005).

Resoluções como essa acabam, de certa forma, dificultando o processo de reciclagem dos filtros usados, já que a quantidade de OLUC no interior desses componentes não é financeiramente atrativa, e destinações diferentes da prevista na Resolução 362/05 estão sujeitas a sanções penais sob a Lei 9.065/98, 
que dispõe de punições derivadas de condutas e atividades lesivas ao meio ambiente (BRASIL, 1998).

O filtro de óleo lubrificante automotivo se mostra um oponente de força contra o meio ambiente devido suas características físicas e químicas, que dificultam o processo de reciclagem. A NBR 10.004 (ABNT, 2004) classifica os resíduos sólidos da seguinte forma:

I. Resíduo classe I-Perigosos;

II. Resíduo classe II - Não perigosos;

a. Resíduo classe II A - Não inertes;

b. Resíduo classe II B - Inertes;

Aqueles que apresentam pelo menos uma das características como inflamabilidade, corrosividade, reatividade, toxicidade ou carcinogenicidade são classificados como resíduos classe I - perigosos, sendo que os demais tipos, ao entrarem em contato com os dessa classe, se contaminam e passam a ser classificados como perigosos (ABNT, 2004).

Como o item descartado em questão possui, em seu interior, uma quantidade significativa de OLUC, que, por sua vez, possui em sua composição elementos tóxicos como cromo, cádmio, chumbo e arsênio, sendo essas substâncias bioacumulativas e que trazem sérios problemas de saúde, dessa forma se faz necessário uma atenção especial no tratamento deste resíduo segundo análise de Muniz e Braga (2015).

\section{IMPACTOS AMBIENTAIS PROVOCADO PELO DESCARTE INADEQUADO DOS FILTROS DE ÓLEO LUBRIFICANTES}

O descarte inadequado de resíduos como os filtros de óleo lubrificantes traz prejuízos de grandes proporções ao meio ambiente, uma vez que a sua construção possui componentes que, quando contaminados, trazem agravos não só para o meio ambiente, mas também para saúde pública (SOHN, 2007). Segundo o Guia Básico de Gerenciamento de Óleos Lubrificantes Usados ou Contaminados, o OLUC, que é o mesmo encontrado no interior desses filtros, pode trazer prejuízos da seguinte forma:

- Quando descartado diretamente ao solo, o OLUC contido no interior dos filtros, por não ser biodegradável, inutiliza o solo e leva dezenas de anos para desaparecer, trazendo, então, prejuízos à agricultura, à fauna e à flora;

- O potencial de degradação de um litro de OLUC, facilmente encontrado no interior dos filtros, pode contaminar 1 milhão de litros de água, sendo ainda que essa mesma quantidade de óleo na superfície da lâmina d'agua pode chegar a se espalhar por $1.000 \mathrm{~m}^{2}$; 
- Caso seja lançado nos sistemas de esgotos, o mesmo pode comprometer o funcionamento das estações de tratamento, chegando até mesmo a parar o seu funcionamento;

- Se for queimado, o que, nesse caso, se constitui um crime ambiental, a concentração de poluentes resultantes de sua queima pode chegar a um raio de $2 \mathrm{~km}$;

Dessa forma, o OLUC contido nos resíduos de filtro de óleo automotivo se mostra um oponente de peso contra o meio ambiente, sendo que outros componentes do filtro também possuem características de mesma familiaridade quando se refere à degradação. Os anéis de vedação, por exemplo, são constituídos de borracha sintética e possuem um tempo de decomposição indeterminado pela natureza (VELOSO, 2018). Posto isto, é possível afirmar que esse seria um dos componentes dos filtros que levaria mais tempo para se desintegrar, já que, ainda em Veloso (2018), é possível analisar o tempo de decomposição do metal, que pode chegar a cem anos, e do papelão, que compõe o meio filtrante que dura, aproximadamente, seis meses.

As dificuldades na segregação do material envolvido na construção dos filtros acabam afetando o interesse no processo de reciclagem, sendo que, nos dias atuais é possível afirmar que a pegada ecológica do homem não está em um patamar de sustentabilidade (PINHO, 2018), o que preocupa uma parte da humanidade que busca uma melhor qualidade de vida para sua própria geração e para as futuras.

\section{LEGISLACÕES}

Ainda que haja resoluções concernentes ao tratamento do OLUC como as resoluções 362/2005 e 450/2012 (CONAMA), há uma carência notória de legislações que abordem, de forma específica, o tratamento e destinação dos resíduos sólidos provenientes de trocas de óleo e manutenções automotivas especialmente os filtros de óleo utilizados, visto que são caracterizados como resíduo perigoso e, segundo a PNRS - Lei 12.305/2010, resíduos sólidos perigosos que provêm de atividades comerciais não podem ser destinados ao mesmo tratamento de resíduos comuns (BRASIL, 2010).

A PNRS é a única legislação brasileira que, de alguma forma, define algum tipo de tratamento aos resíduos de natureza perigosa. Ela traz como um de seus objetivos a "redução do volume e da periculosidade dos resíduos perigosos" (BRASIL, 2010), além de atribuir aos geradores a responsabilidade compartilhada pelo ciclo de vida dos produtos, conferindo-lhes o compromisso de "[...] minimizar o volume de resíduos sólidos e rejeitos gerados, bem como para reduzir impactos causados à saúde humana e à qualidade ambiental decorrentes do ciclo de vida dos produtos [...]" (BRASIL, 2010).

Essa lei ainda aborda no art. 20, o Plano de Gerenciamento de Resíduos Sólidos (PGRS), um documento dotado de diretrizes para o tratamento adequado dos resíduos sólidos, tornando as organizações comerciais responsáveis por sua geração. Outra medida importante, abordada no art. 33 da lei em questão, é a implementação da logística reversa, que tanto os fabricantes, os importadores, 
distribuidores e comerciantes são responsáveis pelo retorno dos produtos após o uso, levando em consideração a "viabilidade técnica e econômica da logística reversa, bem como o grau e a extensão do impacto à saúde pública e ao meio ambiente dos resíduos gerados" (BRASIL, 2010).

\section{IMPORTÂNCIA DA LOGÍSTICA REVERSA PARA OS FILTROS DE ÓLEOS LUBRIFICANTES AUTOMOTIVOS USADOS}

O aumento no consumo por veículos automotores nos últimos anos trouxe como consequência a grande quantidade de resíduos gerados nas manutenções, e com os filtros de óleos lubrificantes não foi diferente, nas coletas realizadas pela ABRAFILTROS através do Programa de Descarte Consciente desde o ano de 2012 até outubro de 2018 foram recolhidos 12.273 .398 filtros usados (ABRAFILTROS, 2018). Essa iniciativa consiste da implantação de um sistema de logística reversa que visa dar um tratamento adequado para esses produtos após seu consumo. A Política Nacional de Resíduos Sólidos descreve o sistema de logística reversa como:

Instrumento de desenvolvimento econômico e social caracterizado por um conjunto de ações, procedimentos e meios destinados a viabilizar a coleta e a restituição dos resíduos sólidos ao setor empresarial, para reaproveitamento, em seu ciclo ou em outros ciclos produtivos, ou outra destinação final ambientalmente adequada (BRASIL, 2010).

Iniciativas como essas podem mudar o cenário atual do descarte de resíduos que possuem um alto potencial de degradação do meio ambiente e prejuízo à saúde pública, pois, dessa forma, o ciclo de vida dos filtros não acabará no momento que for entregue ao cliente, e sim quando retornar ao ponto de origem, ou seja, seus fabricantes. Porém, para que medidas como essas venham realmente funcionar, é preciso de incentivos tanto da iniciativa privada como do Estado, uma vez que a falta de leis que realmente direcionem essa responsabilidade ainda é um grande desafio para essa problemática. A PNRS ainda possui lacunas que facilitam a exclusão da responsabilidade dos fabricantes e consumidores, já que o tratamento desse resíduo não é trazido como foco principal.

Com a implantação da logística reversa, é possível realizar um reprocessamento desses filtros, aproveitando todas as partes que compõem o mesmo, entretanto os custos envolvidos nesse processo se mostram como um forte desafio, ainda que não haja dúvidas quanto à eficiência da logística reversa desses produtos que, além de gerar uma melhoria considerável ao meio ambiente, melhora o cenário econômico através da geração de empregos para os envolvidos no processo de reciclagem desse resíduo.

Entretanto quantidade de pontos de troca de óleo/filtros aumentou, juntamente com a crescente frota de veículos no Brasil, já que, somente nos últimos oito anos, obteve-se um aumento de $54 \%$ de automóveis circulando nas vias do país, e esses números refletiram em pequenas cidades como Alagoinhas, situada no interior do estado da Bahia, que teve um aumento em sua frota de 
automotores da categoria leves de, em média, $6,83 \%$ ao ano no mesmo período, conforme gráfico 1 (DENATRAN, 2018).

Gráfico 1 - Expansão da frota de automóveis Alagoinhas - BA de 2010 a 2018



Fonte: Adaptado de DENATRAN (2018)

Os pontos de troca de óleo/filtros, com a expansão do mercado automotivo, mudaram significativamente - essa atividade, praticada anteriormente apenas por oficinas, abriu as portas para novos horizontes, tendo em vista que, na pesquisa de campo realizada em Alagoinhas, foi possível identificar os mais variados segmentos de manutenção realizando esse procedimento, dentre os quais pequenas e grandes oficinas, concessionárias de veículos, empresas especializadas em alinhamento, balanceamento e trocas de pneus que acrescentaram essa atividade à sua carteira de serviços. A investigação de Cerqueira et al. (2018) mostra que a atividade de troca de óleo/filtros possui um valor rentável atrativo, e dessa forma os postos de abastecimentos também agregaram esse serviço ao seu portfólio, realizando altos investimentos em suas instalações, aquisição de equipamentos, ferramentais e capacitação da mão de obra para atender à crescente demanda por esse tipo de atividade.

\section{FILTROS DE ÓLEOS LUBRIFICANTES}

O filtro de óleo lubrificante do motor dos carros é considerado um dos componentes mais importantes do sistema de lubrificação dos veículos automotores, pois através desse, é possível filtrar todas as impurezas provenientes do funcionamento do motor (CASTRO; BARBOSA, 2014). Negligenciar a troca desses filtros reduz consideravelmente a vida útil do motor e, por esse motivo, fabricantes de automóveis recomendam a troca periódica dessas peças que ficam instaladas diretamente no motor.

Tais filtros são classificados, segundo Pasqualetto, Machado e Morais (2017), após vida útil definida pelo fabricante como resíduos perigosos classe I (ABNT NBR 10004:2004), já que indícios de óleo saturado e metais pesados são facilmente encontrados nos mesmos. A Resolução CONAMA 450/12, que altera a Resolução CONAMA 362/05, define as especificações necessárias à gestão do OLUC (Óleo Lubrificante Usado ou Contaminado), contudo não trata sobre o 
descarte adequado do filtro de óleo utilizado, sendo este um agente nocivo ao meio ambiente e à saúde pública.

\section{Composição dos Filtros de Óleos Lubrificantes Automotivos}

Os filtros de óleos lubrificantes possuem geometrias e características específicas, de acordo com o modelo de veículo para qual os mesmos foram projetados, sendo que, atualmente, essas peças são fabricadas em tamanhos mais compactos em função dos novos modelos de carros fabricados no Brasil, mas seu princípio de funcionamento é semelhante a todos. Na figura 1, é possível detalhar as partes que compõem esse item tão importante para o sistema de lubrificação dos motores a combustão.

Figura 1 - Perspectiva explodida de um filtro de óleo lubrificante
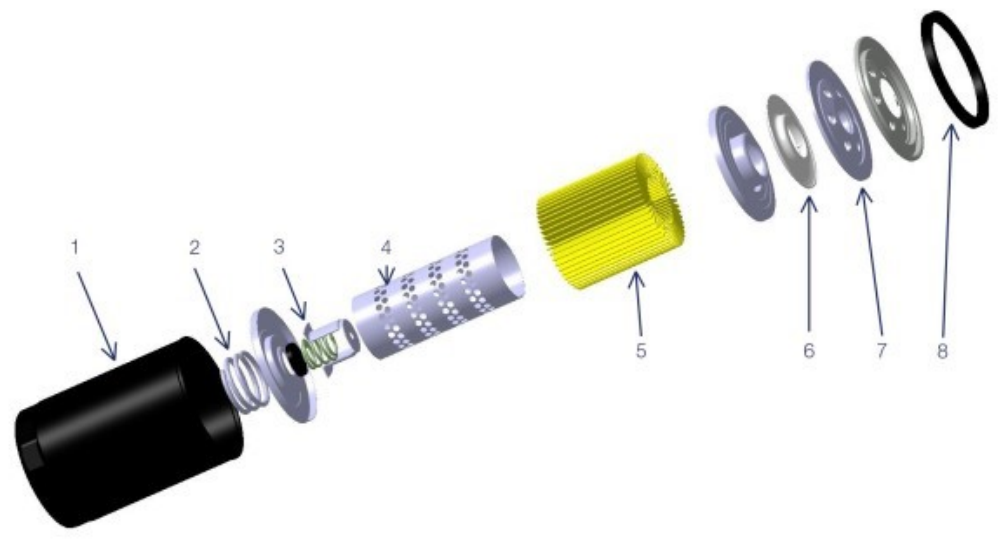

Fonte: Mahle (2018)

1- Carcaça. 2 - Mola. 3 - Válvula de By-pass. 4 - Núcleo interno. 5- Elemento do filtro. 6 - Válvula anti-dreno. 7 -Tampa. 8 - Vedação.

\section{METODOLOGIA}

A pesquisa em questão é de cunho exploratório e descritivo sobre a gestão dos filtros de óleos lubrificantes automotivos pós consumo na cidade de Alagoinhas - BA, situada no interior do estado a $117 \mathrm{~km}$ da capital baiana, onde esse município possui uma frota de veículos leves e pesados de 34.138 unidades (DENATRAN, 2018). Os dados levantados no presente estudo obtiveram-se através de um estudo de caso juntamente com uma pesquisa bibliográfica, onde nessa foi possível analisar informações de artigos, revistas, livros, leis e resoluções. Dessa forma foram realizadas visitas nos pontos de trocas de óleo/filtros com intuito de diagnosticar a gestão do resíduo em questão através de entrevistas orientadas (Apêndice A e B).

A área de estudo foi delimitada através do aplicativo Waze, popularmente utilizados pelos condutores devidos as inúmeras funcionalidades, dentre essas foi possível identificar a quantidade de pontos de troca de óleo/filtros cadastrados no aplicativo usando a extensão do Google Map no período de agosto de 2017 a agosto de 2018 , onde foi possível entrevistar $60 \%$ dos 20 pontos vinculados ao software. A área de estudo logrou-se em um raio de 7 km da Praça Rui Barbosa, 
centro da cidade, essa área corresponde a $21,74 \%$ da sua extensão territorial (IBGE, 2018), dessa forma foi possível gerar um estudo de natureza quantitativa e qualitativa sobre a gestão desse resíduo.

\section{RESULTADOS E DISCUSSÃO}

\section{GERENCIAMENTO DOS FILTROS DE ÓLEOS LUBRIFICANTES PÓS-CONSUMO}

Na pesquisa de campo realizada na cidade de Alagoinhas, foi possível gerar um levantamento de dados de extrema relevância sobre a gestão dos filtros de óleo lubrificantes usados, tornando-se evidente o desconhecimento de normas e leis sobre resíduos perigosos classe I da NBR 10004:2004. Análises como essa mostram a necessidade na melhoria do gerenciamento desse resíduo. No entanto, mesmo com a falta de incentivos e apoio, algumas empresas buscam adotar procedimentos internos que podem minimizar os danos ao meio ambiente e saúde pública.

\section{Segregação dos Resíduos}

A separação dos resíduos nesse tipo de manutenção é uma das fases mais importantes para uma destinação final adequada, pois nessa fase é feita a segregação de todo material gerado por esse tipo de manutenção, como pode ser visto na figura 2, sendo possível, dessa forma, evitar a contaminação de resíduos classe II com os de classe I - sendo, respectivamente, classificados como não-perigosos e perigosos (ABNT, 1992). Nos pontos de troca de óleo/filtro, é possível ainda encontrar resíduos como estopas sujas somente com sólidos provenientes das estradas onde circulam esses veículos. Sendo assim, torna-se claro que a má gestão desse material pode transformá-lo em resíduo de classe I e, consequentemente, mais um passivo para o meio ambiente.

Figura 2 - Recipiente de armazenamento tipo contêiner de resíduos

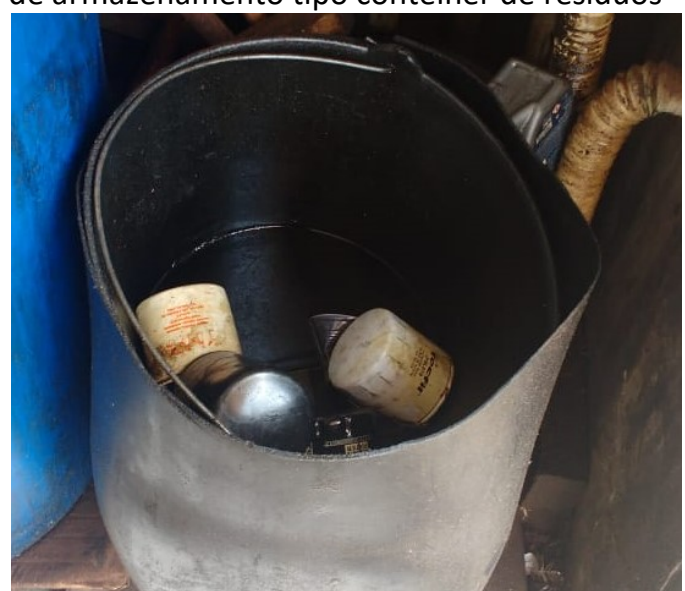

Fonte: Elaborado pelos autores (2018)

No entanto, os proprietários desses comércios adaptam os mais diversos tipos de recipientes que podem ser enquadrados como contêiner de resíduos segundo NBR 12235/1992 que são definidos como: "Qualquer recipiente portátil no qual o resíduo possa ser transportado, armazenado, tratado ou, de outra forma, manuseado" (ABNT, 1992). Dessa forma os profissionais envolvidos nesse tipo de manutenção reduzem a quantidade de resíduos de óleo nas embalagens. 


\section{Armazenamento}

Através do estudo realizado no município de Alagoinhas, foi possível constatar que o armazenamento, fase que antecede a destinação final dos resíduos, é feito pelos proprietários dos pontos de troca de óleos/filtros, sendo que o manuseio de resíduos dessa natureza necessita de uma atenção especial para que o mesmo evite contato com o meio ambiente (CRUZ; NERIS; MENEZES, 2018). Esse procedimento é realizado de forma rotineira no intuito de tratar esse passivo de forma eficiente. No entanto, essas empresas tentam cumprir os itens da NBR 12235:1992 - Armazenamento de Resíduos Sólidos Perigosos, como pode ser visto na figura 3 .

Figura 3 - Recipiente de armazenamento tipo tambor

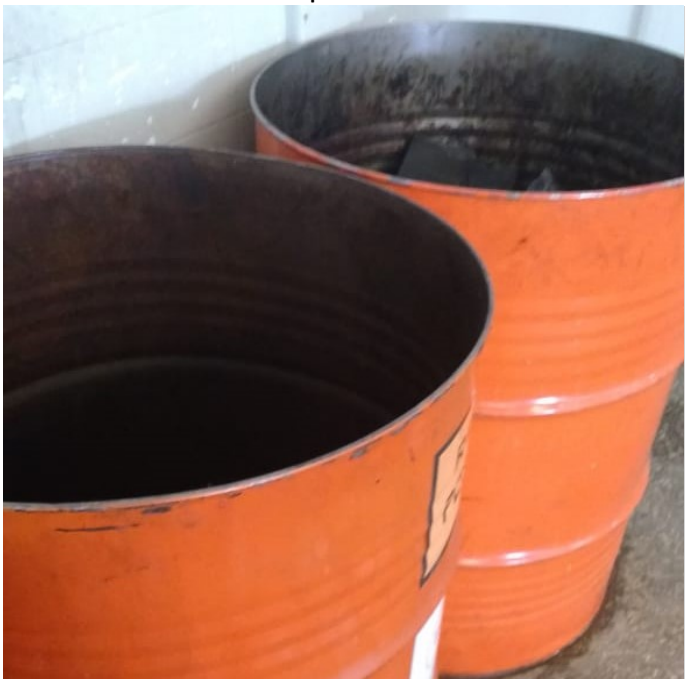

Fonte: Elaborado pelos autores (2018)

Os tambores é uma das formas mais econômicas de realizar o armazenamento adequado antes do descarte final, pois em muito dos casos analisados nesse estudo, foi possível constatar um reaproveitamento dos tambores de óleos lubrificantes que são vendidos nessas organizações, já que os mesmos atendem as características previstas em norma que são: "Recipiente portátil, cilíndrico, feito de chapa metálica ou material plástico, com capacidade máxima de 250L." (ABNT, 1992). Dessa forma, os recipientes para acondicionamento dos resíduos são pintados conforme resolução do CONAMA, 275 de abril de 2001 e usados com essa finalidade.

\section{Destinação final}

A destinação final dos filtros de óleos lubrificantes é um grande problema, não só para a cidade de Alagoinhas - BA, mas para o Brasil, tendo em vista a falta de iniciativas tanto da parte privada como da parte pública, conforme evidenciado nas entrevistas que foram realizadas aos proprietários desses negócios. Em análise aos dados coletados, pode se afirmar que existe um progresso de melhoria contínua nos processos internos desses estabelecimentos, sendo perceptível que, mesmo desconhecendo a NBR 14001:2015 - Sistema de Gestão Ambiental, os envolvidos nesse processo estão melhorando sua gestão ambiental a cada dia. 
No entanto, nem tudo depende dos proprietários, dado que a destinação final e tratamento adequado é realizado por terceiros. Ainda assim, segundo os dados coletados, a falta de parceiros para tratar esse passivo só agrava a situação, já que $25 \%$ dos entrevistados afirmaram que destinam esses resíduos para coleta pública municipal. Informações como essa denuncia a inobservância dos órgãos responsáveis. A investigação de Verde, Scalize e Arruda (2015), mostra uma situação semelhante em Inhumas - GO, onde o percentual chega a $30 \%$, sendo que essa alternativa degrada o meio ambiente de diversas formas, assim como impacta a saúde pública.

\section{GESTÃO DOS FILTROS PÓS CONSUMO NA CIDADE DE ALAGOINHAS - BA}

Outros dados apurados no estudo feito na cidade de Alagoinhas agravam ainda mais a situação, onde $41,7 \%$ dos pontos de troca de óleo/filtros entrevistados desconhecem a existência da NR-20, norma regulamentadora referente à segurança e à saúde no trabalho com inflamáveis e combustíveis, o que evidencia a falta de investimento e fiscalização. Ainda sobre o quesito em questão, o gráfico 2 mostra um percentual expressivo quanto a inobservância da gestão desses resíduos nos pontos de serviços de trocas de óleo/filtros.

Gráfico 2 - Fiscalização dos Pontos de Trocas de Óleo/Filtros no ano 2018

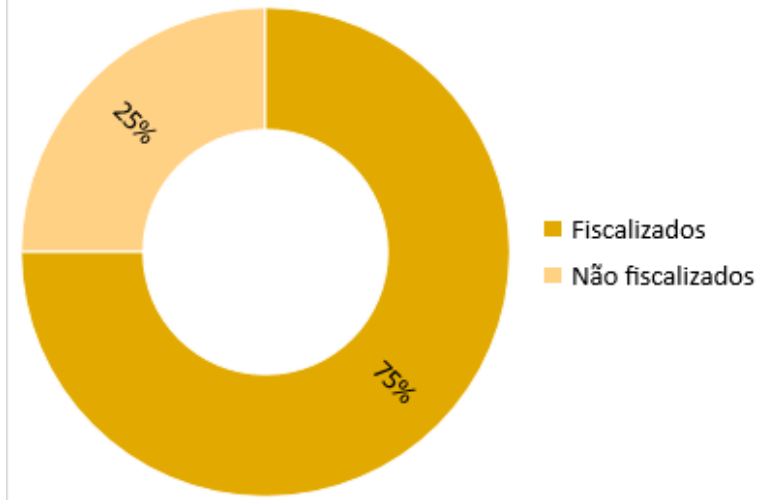

Fonte: Elaborado pelos autores (2018)

A falta de inspeção em $25 \%$ dessas organizações é algo preocupante para uma cidade que possui uma frota que vem crescendo, em média, 6,83\% ao ano desde 2010 (DENATRAN, 2018), consequentemente, gerando mais resíduos provenientes dessa manutenção. O estudo de Mota e Figueiredo (2017), reforça a teoria de ineficiência das vistorias realizada nessas empresas, que em muitas das vezes realiza atividades sem conhecimento algum dos danos causados pelo OLUC e os resíduos contaminados pelo mesmo. A troca de óleos/filtros é bastante intensa, pois, somente no raio de estudo onde foram entrevistados $60 \%$ dos estabelecimentos no mês de agosto de 2018, foram realizadas 1560 substituições desses filtros, já se tratando de um número expressivo, mesmo não englobando a cidade por um todo.

Nada obstante, outros números obtidos nesse estudo são mais preocupantes, sendo atrelados diretamente aos itens já dispostos nessa pesquisa. O gráfico 3 mostra a disposição final desses resíduos na cidade de Alagoinhas, no qual $25 \%$ dos entrevistados afirmaram que esses resíduos são destinados a coleta pública municipal, que direciona todos os seus resíduos para 
o aterro sanitário. Realizando uma análise do mês de agosto de 2018 , é possível afirmar que foram lançados ao meio ambiente 390 filtros usados de forma totalmente inadequada.

Gráfico 3 - Destinação Final dos Filtros Pós Consumo na cidade de Alagoinhas - BA

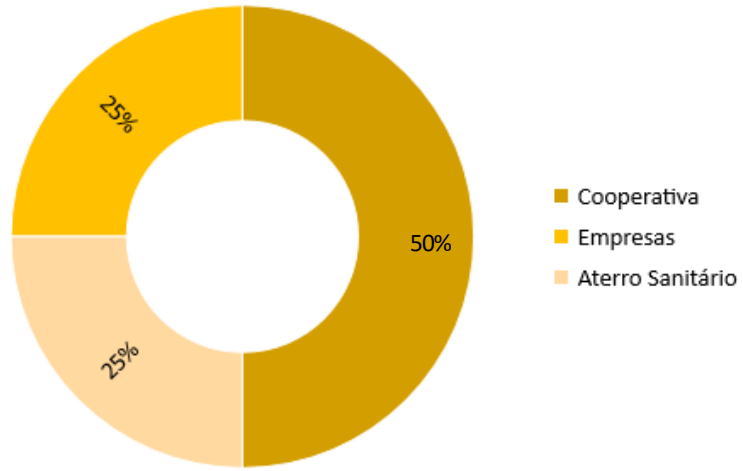

Fonte: Elaborado pelos autores (2018)

Um dado interessante sobre a destinação final dos filtros pós consumo é o percentual desses resíduos que são tratados por cooperativas. Entre os entrevistados, 50\% afirmaram que esse passivo é tratado por essas organizações, já os $25 \%$ restantes revelaram que existem empresas parceiras para realizar a destinação correta desses resíduos. Logo, $75 \%$ dos resíduos mencionados nessa pesquisa recebem algum tipo de tratamento, porém é preciso muito esforço para melhorar ainda mais tal estimativa.

Dentro desses esforços para minimizar os impactos ambientais fica clara a necessidade de melhoria em alguns dos estabelecimentos entrevistados, o gráfico 4 mostra o percentual dessas organizações comerciais que não possuem um procedimento adequado para separação dos resíduos provenientes dessa manutenção, dessa forma uma simples estopa contaminada pelo OLUC se torna um vilão para o meio ambiente.

Gráfico 4 - Separação dos resíduos provenientes da troca de óleo/filtro

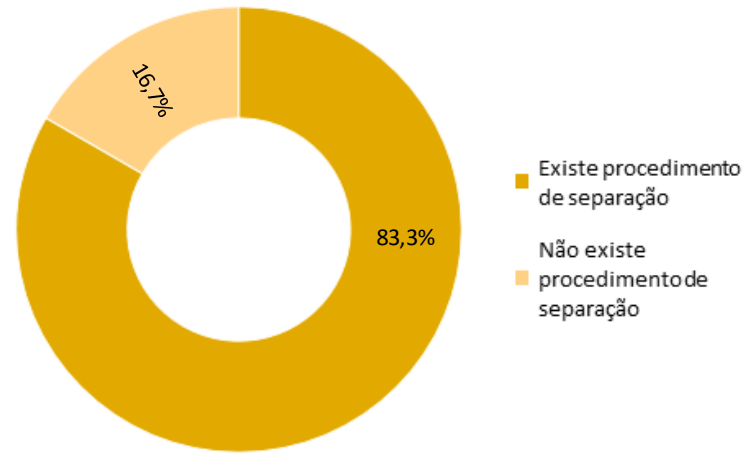

Fonte: Elaborado pelos autores (2018)

Dentre todos os entrevistados é possível afirmar que 100\% deles buscam separar o óleo contido no interior dos filtros e armazenar os mesmos em locais apropriados antes do descarte final. Mas $16,7 \%$ dos resíduos são destinados de qualquer forma, misturados com os mais variados tipos de materiais. 
Outro fator importante descoberto nessa investigação é que $66,7 \%$ desses comércios possuem um procedimento de tratamento dos OLUC gerado na limpeza das mão e ferramentais. Nesse cenário são usadas pias de lavagem especificas para esse procedimento, onde a água contaminada por sabão e óleo é direcionada para caixas de separação. Dessa forma é concebível a extração do OLUC de forma eficaz sem que o mesmo seja direcionado para o meio ambiente.

Ainda no estudo realizado na cidade de Alagoinhas foi possível buscar dados anuais de uma das organizações entrevistadas, o resultado obtido referese ao período de agosto de 2017 a agosto de 2018. A quantidade de trocas de óleo/filtros mostra uma dura realidade para o meio ambiente como pode ser visto no gráfico 5 que poderia ser minimizado através de um programa de logística reversa eficiente.

Gráfico 5 - Dados anuais de uma organização comercial da cidade de Alagoinhas - BA



Fonte: Elaborado pelos autores (2018)

A carência de programas como logística reversa nessa região só agrava a situação, tendo em vista que iniciativas dessa natureza mudam consideravelmente as estatísticas já mostradas nesse estudo, onde cerca de $58,3 \%$ afirmaram que não existe nem um programa de LR. Dessa forma, é possível enxergar que alguns empresários dos pontos de trocas de óleo/filtros utilizam de alternativas inadequadas para descarte desses resíduos, alternativas essas que vão na contramão da preservação do meio ambiente e da saúde pública.

A inexistência de programas de logística reversa para esses resíduos é algo excepcionalmente preocupante, já que esses, após sua vida útil, são classificados como resíduos perigosos de classe I com alto potencial de poluição (ABNT NBR 10004:2004). No entanto, 33,3\% dos profissionais envolvidos desconhecem a destinação final desse material e seus impactos, o que se torna uma estatística preocupante, já que $66,7 \%$ desses estabelecimentos nunca receberam propostas para reciclagem desse material.

$\mathrm{Na}$ conjuntura atual no tratamento desses resíduos, fica clara a necessidade de uma supervisão mais rigorosa quanto ao tratamento adequado dos filtros de óleos lubrificantes automotivos pós consumo. A implantação de processos internos nos pontos de trocas de óleo/filtros, como a segregação dos resíduos e recipientes adequados para armazenagem antes do descarte final, 
mostra atendimento aos requisitos estabelecidos na NBR 12.235/1992, que trata do armazenamento de resíduos sólidos perigosos. Porém, ainda são necessários incentivos externos e leis direcionados a essa problemática, para que se possa melhorar o tratamento de um passivo cujo volume tem crescido gradativamente no Brasil.

\section{CONCLUSÃO}

Conforme os dados explicitados, percebe-se que a gestão dos filtros de óleo utilizados em Alagoinhas-BA é feita por boa parte dos estabelecimentos que realizam trocas de óleo e manutenções automotivas. Entretanto, ainda há um longo caminho a ser trilhado no que tange a responsabilidade compartilhada entre empresas, consumidores e poder público, visando promover uma maior conscientização dos riscos socioambientais causados pelo descarte inadequado desse resíduo, visto que, ainda, uma grande porcentagem dos pontos de troca de óleo não possuem sequer conhecimento sobre a importância das normas e legislações que abrangem o manejo e gestão de resíduos perigosos.

Ainda é evidente que a fiscalização, em boa porcentagem dos participantes entrevistados, não é feita de forma veemente. A falta de cobrança com a gestão dos filtros de óleo utilizados deixa claro que, nem os órgãos fiscalizadores, ou mesmo o poder público, dão a importância devida a essa questão.

Dessa forma, pode-se concluir que é preciso aguçar a percepção das partes envolvidas no que se refere às ameaças trazidas por essa problemática, a começar por uma maior rigorosidade dos órgãos fiscalizadores, além de maior incentivo do poder público por medidas como reciclagem e logística reversa dos filtros após o uso, da mesma maneira que, fornecer locais adequados para sua disposição final. Por fim, consumidores precisam também estar cientes de sua responsabilidade na aquisição destes itens, preocupando-se com a diminuição da geração desses resíduos e com a importância de exigir das empresas o uso de produtos que causem menores impactos ao meio ambiente e sociedade de forma geral. 


\title{
Oil filter management post-consumption automotive lubricants: case study at oil change points in the city of Alagoinhas -BA.
}

\begin{abstract}
The expansion of the acquisition of motor vehicles in recent years has resulted in increased waste generated by vehicle maintenance, and waste from this activity, especially the lubricating oil filters used, has a high power of environmental degradation and damage public health if they are disposed of incorrectly. While aware of the dangers to these associates, it is notable that public and private initiatives have been neglected to properly address these liabilities. The case study conducted in the city of Alagoinhas BA shows the reality of improper disposal and the effort of the owners to mitigate the damage caused by filters after their consumption. The field research carried out at the oil change points registered in the Waze application shows the need for more incisive initiatives to treat this waste, which are often improperly discarded.
\end{abstract}

KEYWORDS: Oil filters. Automotive maintenance. Oily waste. 


\section{REFERÊNCIAS}

ABNT. Associação Brasileiras de Normas técnicas. NBR 10004: Resíduos Sólidos Classificação. Rio de janeiro, 2004.

ABNT. Associação Brasileiras de Normas técnicas. NBR 12235: Armazenamento de resíduos sólidos perigosos. Rio de janeiro, 1992.

ABNT. Associação Brasileiras de Normas técnicas. NBR 14001: Sistemas de Gestão Ambiental - Requisitos com Orientações para uso. Rio de janeiro, 2015.

ABRAFILTROS (Associação Brasileira das Empresas de Filtros e seus Sistemas Automotivos e Industriais). Programa de Descarte Consciente. Santo André - SP: ABRAFILTROS, 2018. Disponível em:

<https://www.abrafiltros.org.br/descarteConsciente/> Acesso em: 06 dez. 2018.

BARROS, M. V.; PIEKARSKI, C. M.; TESSER, D. P. Análise do Panorama da Logística Reversa no Brasil em Termos de Óleos Lubrificantes. 9o Forum Internacional de Resíduos Sólidos. Porto Alegre, RS, 2018.

BRASIL. Lei 9605, de 12 fevereiro de 1998. Dispõe sobre as sanções penais e administrativas derivadas de condutas e atividades lesivas ao meio ambiente, $\mathrm{e}$ dá outras providências. Disponível em:

<http://www.planalto.gov.br/ccivil_03/leis/19605.htm> Acesso em: 26 ago. 2019.

BRASIL. Lei 12.305, de agosto de 2010. Política Nacional de Resíduos Sólidos. Disponível em: < http://www.planalto.gov.br/ccivil_03/_Ato20072010/2010/Lei/L12305.htm> Acesso em: 08 out. 2018.

CASTRO, F. D.; BARBOSA, S. Evolução, Manutenção e Tendências. Motores Automotivos, 1aed. Porto Alegre, RS - Editora Universitária da PUCRS, 2014.

CERQUEIRA, G. R.; LIMA, I. T. R.; LIMA, J. L. M.; ANDRADE, J. R. C. Estudo de Caso da Logística Reversa de Óleos Lubrificantes e suas Embalagens na Cidade de Aracaju. X SIMPROD - Sustentabilidade e Meio Ambiente, São Cristóvão, SE, 2018.

CONAMA (Conselho Nacional do Meio Ambiente). Resolução № 275. Brasília DF, 2001. Disponível em: < http://www2.mma.gov.br/port/conama/legiabre.cfm?codlegi=273> Acesso em: 07 dez. 2018.

CONAMA (Conselho Nacional do Meio Ambiente). Resolução № 362. Brasília DF, 2005. Disponível em: <

http://www2.mma.gov.br/port/conama/legiabre.cfm?codlegi=466> Acesso em: 21 out. 2018.

CONAMA (Conselho Nacional do Meio Ambiente). Resolução № 450. Brasília DF, 2012. Disponível em: <

http://www2.mma.gov.br/port/conama/legiabre.cfm?codlegi=674> Acesso em: 07 dez. 2018. 
CRUZ, D. M. B.; NERIS, L. M.; MENEZES, J. D. S. Gestão ambiental aplicada a postos de abastecimento de combustíveis. Revista Gestão Industrial, Ponta Grossa, v. 14, n. 4, p. 1-17, out./dez. 2018. crossref

DENATRAN (Departamento Nacional de Trânsito). Frota de Veículos 2018. Disponível em: <https://www.denatran.gov.br/estatística/635-frota-2018> Acesso em: 30 out. 2018.

IBGE (Instituto de Geografia e Estatística Brasileira). Disponível em: < https://cidades.ibge.gov.br/brasil/ba/alagoinhas/panorama> Acesso em: 30 set. 2018.

IBGE (Instituto de Geografia e Estatística Brasileira). Disponível em: <https://sidra.ibge.gov.br/tabela/6579\#resultado> Acesso em: 06 out. 2019.

MOTA, A. K. V.; FIGUEIREDO, G. L. A. A Destinação do Óleo Lubrificante Usado ou Contaminado OLUC nas Oficinas Mecânicas em uma Pequena Cidade Localizada no Norte do Estado do Tocantins. JNT Facit Business and Technology Journal, v. 3, n. 1, p. 3-15, 2017.

MTE (Ministério do Trabalho e Emprego). NR 20 - Segurança e Saúde no Trabalho com Inflamáveis e Combustíveis. Disponível em: < https://enit.trabalho.gov.br/portal/images/Arquivos_SST/SST_NR/NR-20.pdf> Acesso em: 06 out. 2019.

MUNIZ, I. C.; BRAGA, R. M. Q. L. O Gerenciamento de Óleos Lubrificantes Usados ou Contaminados e suas Embalagens: Estudo de Caso de uma Empresa de Logística na Região Norte do Brasil. Revista Eletrônica Sistema e Gestão, v. 10, n. 3 , p. 442-457, 2015. crossref

PASQUELETTO, A.; MACHADO, R. L.; MORAIS, J. Estimativa dos Resíduos de Óleos Lubrificantes e de Componentes de Filtros Lubrificantes da Frota de Veículos Goiana e Brasileira. Revista Engenharia Ambiental, v. 14, n. 2, p. 21-43, jul./dez. 2017.

PINHO, M. M. DE RESÍDUO A RECURSO: A Reciclagem / Reutilização de Materiais Não Biodegradáveis em Arquitetura. Dissertação de Mestrado, Universidade do Porto, Portugal, 2018.

SOHN, H. Guia Básico de Gerenciamento de Óleos Lubrificantes Usados ou Contaminados. APROMAC - Associação de Proteção ao Meio Ambiente de Cianorte. Cianorte, SP, 2007.

VELOSO, Z. M. F. Ciclo de Vida dos Pneus. Ministério do Meio Ambiente. Disponível em: <http://www.inmetro.gov.br/painelsetorial/palestras/ZildaMaria-Faria-Veloso-Ciclo-Vida-Pneus.pdf> Acesso em: 08 set. 2019.

VERDE, D. V.; SCALIZE, P. S.; ARRUDA, P. N. Gestão do Óleo Lubrificante Usado e suas Embalagens na Cidade de Inhumas - Go, Brasil. XIX Exposição de Experiências Municipais em Saneamento, Poços de Caldas, MG, 2015. 


\section{FACULDADE SANTÍSSIMO SACRAMENTO}

R. Mal. Deodoro, 118 - Centro, Alagoinhas - BA, 48005-020

Telefone: (75) 3182-3182

\section{PESQUISA DE CAMPO}

OBJETIVO: Diagnosticar a Gestão dos Filtros de Óleos Lubrificantes Automotivos Usados: Estudo de Caso na Cidade de Alagoinhas - BA.

\section{DADOS DA PESQUISA}

\begin{tabular}{|l|l|l|l|}
\hline Entrevistador & Cód. Entrevistado & Data & № Trocas de filtros \\
\hline
\end{tabular}

\section{ESTIONÁRIO}

1 - Os funcionários responsáveis pela troca de óleo/filtros possui treinamento ou conhecimento da NR-20 - Segurança e Saúde no Trabalho com Inflamáveis e Combustíveis?

$\square \operatorname{sim} \square$ Não

2 - É realizada a separação do resíduo oleoso do filtro antes da destinação final?

$\square \operatorname{sim} \square$ Não

3 - Existe uma separação dos resíduos provenientes da troca de óleo/filtro?

(Ex.: Estopas de limpeza contaminada).

$\square \operatorname{sim} \square$ Não

4 - Existe um procedimento interno para tratamento dos resíduos oleosos gerados pela limpeza das mãos e ferramentas?

$\square \operatorname{sim} \square$ Não

5 - Qual o local de armazenamento dos filtros usados antes da destinação final?

$\square$ Deposito apropriado para armazenagem $\square$ Recipientes para coleta

Outros:

6 - Existe alguma fiscalização externa no que se refere a destinação final desses resíduos (filtros usados)?

\section{$\square \operatorname{sim} \square$ Não}

7 - Existe programas de reciclagem ou logística reversa para os filtros usados?

$\square \operatorname{sim} \square$ Não

8 - Já houve propostas para reciclagem desse resíduo?

$\square \operatorname{sim} \square$ Não

9 - Os profissionais envolvidos na troca de óleos/filtros tem conhecimento sobre a destinação correta dos filtros usados?

10 - Qual a destinação final dos filtros lubrificantes usados?

$\square$ Cooperativas de reciclagem;

$\square$ Empresas parceiras;

$\square$ Lixão;

Doutros:

Alagoinhas - BA __ de de 2018 
FACULDADE SANTÍSSIMO SACRAMENTO

R. Mal. Deodoro, 118 - Centro, Alagoinhas - BA, 48005-020

Telefone: (75) 3182-3182

\section{PESQUISA DE CAMPO - DADOS ANUAL}

OBJETIVO: Diagnosticar a Gestão dos Filtros de Óleos Lubrificantes Automotivos Usados:

Estudo de Caso na Cidade de Alagoinhas - BA.

DADOS DA PESQUISA

Dados coletados referente ao período de agosto de 2017 a agosto de 2018.

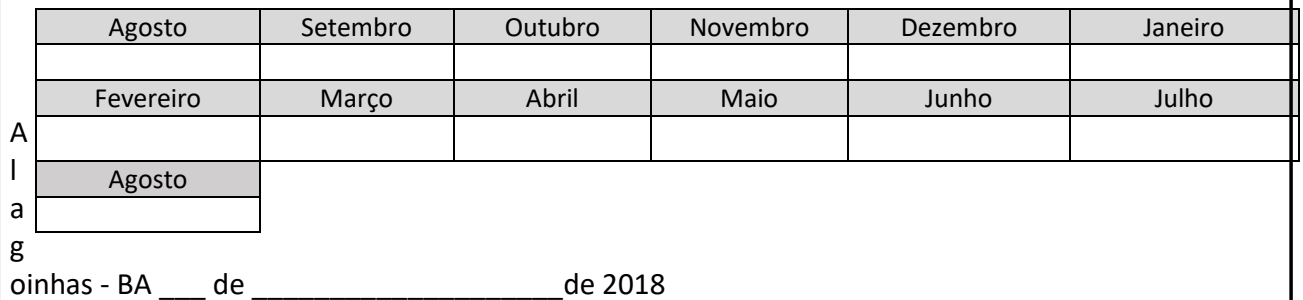

Entrevistado

Recebido: 15 Fev. 2020

Aprovado: 20 Out. 2020

DOI: 10.3895/gi.v16n3.11634

Como citar:

SAMPAIO, A.J. et al. Gestão dos filtros de óleo lubrificantes automotivos pós-consumo: estudo de caso nos

pontos de trocas de óleo na cidade de Alagoinhas -BA. R. Gest. Industr., Ponta Grossa, v. 16, n. 3, p. 22-

40, Jul./Set. 2020. Disponível em: https://periodicos.utfpr.edu.br/revistagi

Correspondência:

Almir de Jesus Sampaio

Faculdade Santíssimo Sacramento (F.SS.S), Alagoinhas, Bahia, Brasil.

Direito autoral: Este artigo está licenciado sob os termos da Licença Creative Commons-Atribuição 4.0

Internacional.

\section{(c) (1)}

